\title{
Systematic review of the uptake and design of action research in published
}

\author{
Carol Munn-Giddings \\ Faculty of Health and Social Care \\ Anglia Ruskin University \\ Essex, UK \\ Andrew McVicar \\ Reader \\ Faculty of Health and Social Care \\ Anglia Ruskin University \\ Essex, UK

\section{Lesley Smith} \\ Freelance Researcher \\ Faculty of Health and Social Care \\ Anglia Ruskin University \\ Essex, UK
}

\begin{abstract}
Action research $(\mathrm{AR})$ is promoted for health care development. A systematic review was undertaken to gain insight into the uptake and designs of practice-based AR. Empirical research papers from 2000 to 2005 were extracted from CINAHL, MEDLINE and British Nursing Index, and two specialist AR journals. The initial search identified 335 papers: $38 \%$ were AR (20\% were phenomenology; $32 \%$ ethnography; $10 \%$ randomised-controlled trials). Further filtering produced 62 AR papers for detailed analysis. Eighty-seven per cent of AR studies involved 'organisational/professional development', or 'educational' settings; only $13 \%$ were directly 'clinical'. Practitioners were the main participants in $90 \%$ of studies. Seventy-two per cent of all participant groups were rated 'active' in the research process, yet $70 \%$ of first (lead) authors were from an academic institution. Patients/carers were generally passive in the research process and absent from the authorship. Ninety per cent of studies used two or more methods, predominantly qualitative. Forty-four per cent of articles identified external funding sources, relatively high for nursing research. Participatory AR has a strong identity in practice-based research, with a diversity of methods. The focus reflects that of nursing research generally. A high level of participation by practitioners is evident but with little equity in authorship. Service user/carer involvement should be given more prominence by researchers.
\end{abstract}

\section{Key words}

action research; methodology; nursing research; participation; research design

\section{Introduction}

The last 15-20 years have seen large-scale reform of health care policy, with concepts of evidence-based practice, research and service user involvement being prominent (Department of Health, 2000, 2001, 2006a,b). There has been a considerable expansion of capacity (i.e., volume) and capability (i.e., skills) within health research during that period, and an increasing engagement of practitioners in that research. Health care research encompasses a number of strategic priorities: decision-making, economic evaluation, outcome evaluation, interdisciplinary education, interdisciplinary needs assessment, interdisciplinary team working, models of service delivery and patient/user involvement (Scott, et al., 1999). Consequently, many research approaches are applicable: 
1. Descriptive research - a description of systems or events pertaining to elements of practice.

2. Exploratory research - an identification of the basic dimensions within a topic area, either because it is an entirely new phenomenon or because new perspectives are sought from a known one.

3. Evaluation research - a mode of inquiry to assess the implementation/value of policies or practice initiatives, using a clearly-differentiated research design.

4. Causal research - the establishing of causal relationships between variables, which tends to involve experimental or correlational designs.

5. Action research $(A R)$ - a process that alternates continuously between enquiry and action as part of the research process.

Recent years have also seen the emergence of evidence-based practice initiatives through which 'researchers are expected to produce evidence for best practice and practitioners are required to implement it' (Somekh, et al., 2005, p. 9), challenging researchers to produce the evidence for practice change. In medical research, the evidence obtained through application of randomised-controlled trials (RCTs) has tended to be the benchmark, yet in health care there appears to be little evidence that such designs are prevalent (Traynor, et al., 2001; McVicar and Caan, 2005), or that they are the most effective means of improving practice (Taylor and Thornicroft, 1996). As an alternative interventional approach, AR appears to be especially appropriate for health care practice (Holter and Schwartz-Barcott, 1993), as it develops 'innovative practices and services over a wide range of health care situations' and 'has the potential to play a role in achieving the goals of the NHS' (Waterman, et al., 2001). This paper provides a review of the uptake and application of AR designs within nursing.

The basic precept of AR is that 'research should lead to change and therefore that change should be incorporated into the research process itself' (Somekh, et al., 2005, p. 11). It is an attractive methodological approach because it bridges the gap between theory and practice (Rolfe, 1996), is problem-focused (Hart and Bond, 1995), is grounded in the reality of practice (Waterman, et al., 1995; Walters and East, 2001), is empowering for nurses (Bellman, 2001) and can be carried out as part of, rather than alongside, practice (Winter and Munn-Giddings, 2001). It seems to be an ideal vehicle for patient/user involvement (Waterman, et al., 2001; Winter and Munn-Giddings, 2001; Beresford, 2003, 2006), and is recommended in the UK to be a significant component in the health R\&D programme (National Co-ordinating Centre for NHS Service Delivery and Organisation, Research and Development, 2001).

It might, therefore, be anticipated that $A R$ is promoted within health care research and within the support that they are recommended to seek from academic institutions (Department of Health, 2005). However, some studies suggest that widespread support for AR by higher education is lacking, raising the possibility of a mismatch between what academics promote in research training, and the (apparent) demands of practice for AR. Thus, whereas doctorallevel study in universities is normally viewed as providing the leading researchers of the future, McVicar and Caan (2005) found that AR figured in only about 5\% of theses from 1983 to 2003. Similarly, Hillier, et al. (2006) identified that just $1 / 31(=3 \%)$ of Health Visiting and Midwifery doctoral theses over a similar period used AR. Additionally, Long and Johnson (2005) found that AR appeared in only approximately $5 \%$ of educational research papers published in a major journal, Nurse Education Today. The reason for the relatively low uptake of $A R$ in health care is unclear.

Education-focused studies provide only a one-sided, unbalanced perspective, and so the assumption of a theory-practice gap may be erroneous. Accordingly, this paper presents a bibliometric survey of publications in nursing that have indeed applied AR, to provide an indication of the level of uptake of AR by practitioners. AR applies complex, collaborative and iterative designs (Normand, et al., 2003), and in performing the review papers were also assessed to provide a more detailed picture of how AR is being applied in nursing. 


\section{Methodology}

This was a systematic review of papers published in CINAHL, MEDLINE and the British Index of Nursing, between 1st January 2000 and 31st December 2005 (accessed during July 2006). These were considered to be the most comprehensive databases of published nursing research, and the most likely to be used by academics and practitioners when constructing a contemporary knowledge base in the field.

\section{AR in comparison with other methodological approaches}

An 'easy' search was initially conducted using the search term 'AR' within the whole document, and this generated 1047 hits. However, a perusal of just a small selection of these identified that searching the whole document usually did not identify papers that were AR studies per se. In view of the logistics of obtaining and examining every publication to ascertain its value to the study, a decision was taken that the search terms would be restricted to 'action research' (Title and Abstract), 'nursing' (Title and Abstract) and 'UK' (whole document). In so doing, it is unlikely that the search comprehensively captured every article involving AR, but it was considered that it would sufficiently identify primary research papers to provide a 'snapshot' of the situation in nursing, analogous to the reviews of doctoral theses (McVicar and Caan, 2005; Hillier, et al., 2006) that provided some of the academic comparators for this review. The search generated 151 articles; removal of duplicate entries (37) left a total of 114 papers.

To place the search into context alongside other research approaches, further searches were conducted in the same electronic databases, using the same fields and over the same review period, by replacing 'AR action research' as a search term with other common methodologies. Repeat entries were removed. The methodologies used in this search were:

- 'Quantitative' or 'qualitative'. This search generated a total of 1021 papers that had applied either quantitative or qualitative methodology. The search terms did not differentiate specific methodologies but provided a broad overview of the situation.

- 'Ethnography', 'phenomenology' or 'RCT'. This search generated a total numberof 209 papers, which when added to the AR papers gave a total of 323 papers that enabled comparison between these specific methodologies.

\section{Analysis of AR designs}

\section{Sample profile}

One objective of the study was to identify the main source of publication (see below) and it was immediately clear from the search that no papers were included from Educational Action Research and Action Research Journal, arguably the two main journals that specialise in AR projects per se (EAR now includes two health and social care editors to extend the readership of that journal) and so a manual search of these journals was conducted over the time period of the review. This produced a further 12 papers, making a new total of 126 AR papers. The non-appearance of Education Action Research and Action Research Journal in the electronic databases suggests a need for publishers to give access to them as clearly this has consequences for access by nurses to relevant practice-focused studies.

This part of the review was concerned with detailed analysis of AR designs in empirical research studies. However, in considering the 126 AR papers it was apparent that nine were 'discussion' papers more applicable to theories of AR, rather than its application, and so these were removed from the sample. Furthermore, although restricting the search to a specific time period and to studies from the UK, some of the papers generated were actually published outside the timescale (35) or were non-UK studies (20). These were considered not appropriate for this analysis and so also were removed. Filtering, therefore, left a final sample of 62 papers, published between 2000 and 2005, that reported primary research studies in the UK and had used AR designs. 
There was no obvious chronological trend in publication of AR, although the distribution of papers was uneven with 2000 and 2005 together providing over half of the sample (Table 1). What was apparent within the database was that a range of terms have been used to define the AR approach: 24 different terms were used, including for example collaborative action research, emancipatory and enhancement action research, participatory research and evaluative action research. In reality, semantics probably exaggerated the diversity of approaches, whereas others were founded in esoteric taxonomy debates not pertinent to the outcomes of this study. This review, therefore, did not make a distinction between the approaches used, and typologies of AR within health and social care will be the subject of a follow-up papers.

\begin{tabular}{|c|c|c|}
\hline Table 1 Distribution of action research (AR) studies over the period 2000-2005 \\
\hline Year of publication & No. of AR studies & \% all AR studies \\
\hline $\mathbf{2 0 0 0}$ & 16 & 26 \\
\hline $\mathbf{2 0 0 1}$ & 5 & 8 \\
\hline $\mathbf{2 0 0 2}$ & 5 & 8 \\
\hline $\mathbf{2 0 0 3}$ & 8 & 13 \\
\hline $\mathbf{2 0 0 4}$ & 8 & 13 \\
\hline $\mathbf{2 0 0 5}$ & 20 & 32 \\
\hline & $\mathbf{6 2}$ & $\mathbf{1 0 0}$ \\
\hline
\end{tabular}

The papers appeared in a wide range of journals. The five most popular (34/62 in total; 55\%) could be categorised as 'academic' rather than 'professional' publications, that is Journal of Clinical Nursing (nine articles), Educational Action Research (seven), Nurse Education Today (seven), Journal of Advanced Nursing (six) and NT Research/Journal of Research in Nursing (five; viz the journal had changed its title in 2005). A 'professional' journal, Nursing Standard, was the sixth most popular (four papers). We recognise the difficulty of dividing journals into 'academic' and 'professional' foci as it implies a hierarchy of knowledge but university-based authors predominated (see Findings) and it seems inevitable that authors based at universities were likely to be mindful of what journals are considered most suitable for the periodic Research Assessment Exercise. Whether or not these journals are likely to be accessed by practitioners or service users is debatable.

\section{Analysis}

Analysis of the 62 AR studies was framed by conventional critiquing principles for research articles viz. location of the study, setting for the research, authorship, methods, participants and source of funding. However, AR is also characterised by collaboration and participation, and so the analysis also considered these aspects. The papers, therefore, were scrutinised for the following.

\section{Location of the study and focus of change (setting)}

The site at which the research took place was noted, as also was the research setting. The latter was based on definitions provided by McVicar and Caan (2005) in their review of research designs in nursing doctoral theses so that comparison could be made with that study. Thus, the setting was identified as organisational or professional development, educational, clinical (including users or carers), historical or public health. Further comparison was made with settings identified by Traynor, et al. (2001) in their large-scale bibliometric review of nursing research from 1988 to 1995 (estimated only - data were recalculated from their data as categories applied in that study were related but different to those here). 
Where authors were based in universities, they were defined as 'academics'. In doing so, it is recognised that many university personnel also have professional nursing qualifications, and perhaps may prefer to define themselves as practitioners. Despite this limitation, the classification was considered useful in providing an approximate overview of the academic/practitioner balance of authorship, and hence of the nature of the collaboration.

\section{Methods/tools used for data collection}

One of the appeals of AR is that it is not aligned to any one method, and that data collection methods may also be part of everyday practice (Winters and Munn-Giddings, 2001); this review provided an opportunity to gauge the range of methods being applied in nursing AR.

\section{The participants and the nature of participation}

Arguably one of the most significant features of AR is that of participation (Waterman, et al., 2001), and the extent to which this takes place is seen by some authors as a significant criterion for validating AR studies (Hope and Waterman, 2003). The nature of participation was evaluated according to whether it was 'active' or 'passive', that is, making a contribution to the research process rather than simply providing information/data for the study. This represented a rather crude attempt to clarify the role of participants in the research process because the amount of information in this respect varied between papers. Nevertheless, the evaluation provided some useful insights into how participation was incorporated into the research designs.

\section{Source of funding}

Nursing research generally is poorly supported by external funders (Traynor, et al., 2001). However, the promotion of $A R$ as a vehicle for practice development (see Background) suggests a potential general willingness to fund AR studies. Accordingly, sources of funding were noted, if provided.

For many studies, much of this information was apparent from the paper's Abstract, but if it was unclear or incomplete then the full paper was examined. In some instances, the 'nature of participation' still remained difficult to evaluate, and some variables were at times difficult to classify because of overlaps (e.g., if the 'focus of change' was practice development, organisational change or patient care). In view of these difficulties, the authors coded six papers each (selected at random) to ensure inter-rater agreement on the classification of variables, and hence to establish validity and reliability of the coding process.

\section{Results}

\section{AR in comparison with other methodological approaches}

Using the terms 'qualitative' or 'quantitative' in the search field identified 807 and 214 qualitative and quantitative designs, respectively, a ratio of 3.8:1. Qualitative methods also dominated in the AR designs (below) in a ratio that was not too dissimilar, which suggests that the apparent alignment of qualitative methods with AR was not particularly out of line with nursing research generally. To gain insight into the application of AR relative to dominant qualitative and quantitative methodologies, the publications of $A R$ were also compared with those for phenomenological and ethnographic approaches, and with those for RCT. AR figured strongly in comparison with these other approaches: 114 articles $(35 \%)$ involved AR, whereas 107 (33\%) were ethnographic, $67(21 \%)$ phenomenological and $35(11 \%)$ used an RCT design. This broad search, therefore, suggests a substantial utilisation of AR designs within nursing research. 


\section{Analysis of AR papers}

Location of the study and focus of change (setting)

The studies were located across a range of health care providers (Table 2); just 22\% were located elsewhere (in universities). Almost all took place within the statutory sector, especially in hospitals $(50 \%)$. None took place within the voluntary sector, an issue that action researchers perhaps need to address particularly in the context of the growth in the mixed economy of care.

\begin{tabular}{|l|c|}
\hline \multicolumn{2}{|l|}{ Table 2 Location of action research (AR) studies } \\
\hline Site of AR & Number of studies (\%) \\
\hline Hospital & $31(50)$ \\
\hline University & $14(22)$ \\
\hline Community & $9(14)$ \\
\hline Residential home & $3(5)$ \\
\hline Nursing home & $2(3)$ \\
\hline GP surgery & $1(2)$ \\
\hline Rehabilitation unit & $1(2)$ \\
\hline Hospital and community & $1(2)$ \\
\hline
\end{tabular}

Table 3 identifies the setting for the AR studies. The table also provides data taken from published surveys to enable comparison with the proportion of settings identified in doctoral research (McVicar and Caan, 2005), and in a broader bibliometric review of nursing research (Traynor, et al., 2001). The latter study had reported publications on both empirical research and nursing theory, and so for closer comparison with data in this review it was necessary for this analysis to include the nine theoretical AR papers that were excluded from the main database for the rest of the analysis. The findings suggest that the settings for AR studies were generally similar to those of related studies, and reflect the high proportion of nursing research that relates to organisational, professional development and educational issues, but a relative lack of clinically-focused issues.

\begin{tabular}{|c|c|c|c|}
\hline Setting & $\begin{array}{c}\text { AR papers } \\
2000-2005 \\
\text { (\%, current } \\
\text { study) } \\
\end{array}$ & $\begin{array}{l}\text { Doctoral theses } \\
1983-2002 \\
\text { (\%, McVicar and } \\
\text { Caan, 2005) } \\
\end{array}$ & $\begin{array}{c}\text { Bibliometrics } \\
\text { 1988-1995 } \\
\text { (recalculated), } \\
\text { (\%, Traynor, et al., 2001) }\end{array}$ \\
\hline Organisational/ProfDev & 59 & 50 & 31 \\
\hline Educational & 17 & 25 & 28 \\
\hline Clinical/users/carers & 11 & 16 & 13 \\
\hline Historical & 0 & 7 & - \\
\hline Public health & 0 & 2 & - \\
\hline Research methodology/issues & $13 a$ & - & 15 \\
\hline Theory/models & - & - & 13 \\
\hline
\end{tabular}


Number of authors, place of work of the authors and nature of collaboration between the authors

Authorship of papers ranged from 1 to 8 authors: in total, the papers reviewed identified 182 authors, of whom just $14(7.7 \%)$ appeared on more than one paper, with nine on two papers and the other five collectively on four papers. The majority of authors collaborated on one AR project, but did not appear again over the period of the search.

The picture appears to be that of relatively few significant leaders in the promotion and undertaking of AR. Seventy-three percent of papers included two or more authors, evidencing collaborative publication. However, the highest single category of authorship was just one author $(17 / 62 ; 27 \%)$, predominantly academic. The place of work either of the sole author or the first author of multi-authored papers (on the assumption that the first author represents the 'lead') identified that $70 \%$ of 'lead' authors (46/62; Table 4) were based either solely in a university or in the RCN Institute. Just $26 \%$ (16/62) were practitioners in the community or hospital. Thus, although practitioners may be actively involved in generating knowledge about their practice, the majority of studies appear to be led by authors located in academic institutions.

Of the 45 papers that involved more than one author, noting the authors' place of work showed that only six studies had no overt university involvement, though even one of those did acknowledge some assistance. Just one paper identified a publication collaboration with carers, and none of the authors from the entire database was a service user.

\begin{tabular}{|l|c|c|}
\hline \multicolumn{3}{|c|}{ Table 4 Place of work of first author (or sole author) of action research papers } \\
\hline Place of work & $\mathbf{N = 6 2}$ & $\%$ \\
\hline Academic (university-based) & 36 & 61 \\
\hline Practitioner (community or hospital) & 16 & 26 \\
\hline Royal College of Nursing Institute & 6 & 6 \\
\hline Practitioner based at University & 2 & 3 \\
\hline Independent Researcher & 1 & 2 \\
\hline Academic based at University and Hospital & 1 & 2 \\
\hline Service users & 0 & 0 \\
\hline Total & $\mathbf{6 2}$ & $\mathbf{1 0 0}$ \\
\hline
\end{tabular}

Range of methods used

Most (56/62; 90\%) studies used two or more methods of data collection, with a maximum of 10 (one study) and the modal value was two (14 studies). A plethora of methods appeared in the papers reviewed: 56 different methods were identified within a total of 162 applications across the 62 papers. The balance was strongly in favour of qualitative methods (124 applications), and relatively little use was made of quantitative methods (38 applications); inferential statistics appeared only rarely. The ratio of 3.3:1 (qualitative:quantitative) appears to be similar to that of nursing research generally (see (a) above). Overall, almost two-thirds of applications (102/162; 63\%) involved just four tools: interviews (30 applications), focus groups (30), questionnaire (27) and observation (15). Thus, the majority of studies were applying what might be considered conventional or traditional research tools, although there was also some evidence of more diverse approaches, for example, reflective diaries were mentioned in 15 of the studies, and creative arts, repertory grid, Q-methodology and written narratives each appeared in individual studies. 
Perhaps not surprisingly, practitioners were the group most frequently involved in AR $(90 \%$ of studies), and only in six studies were they not included amongst participants (post-registration students who participated in education-focused studies were assumed to be employed in practice) (Table 5). This is encouraging in terms of the claim that AR can empower practitioners to develop their own knowledge (Walters and East, 2001). Less encouraging, however, was the small number of service users and carers despite anticipation of greater service user involvement in research (Meyer and Sturdy, 2004; Winter and Munn-Giddings, 2001; Beresford, 2006; National Co-ordinating Centre for NHS Service Delivery and Organisation, Research and Development, 2001).

\begin{tabular}{|l|c|}
\hline Table 5 Participant groups within the 62 papers reviewed \\
\hline Participants & $\begin{array}{c}\text { Number ex-62 studies } \\
(\%)\end{array}$ \\
\hline Practitioners & $30(48)$ \\
\hline Practitioners and service users & $12(19)$ \\
\hline Practitioners, service users and carers & $4(6)$ \\
\hline Practitioners, post-registration students and academics & $4(6)$ \\
\hline Pre-registration students & $2(3)$ \\
\hline Practitioners, service users, carers and academics & $1(2)$ \\
\hline Practitioners and carers & $1(2)$ \\
\hline Practitioners, carers and trustees & $1(2)$ \\
\hline Pre-registration students and researcher & $1(2)$ \\
\hline Post-registration students and academics & $1(2)$ \\
\hline Post-registration students, academics and service users & $1(2)$ \\
\hline Service users & $1(2)$ \\
\hline Academics & $1(2)$ \\
\hline Practitioner/researcher & $1(2)$ \\
\hline Literature review (no participants) & $1(2)$ \\
\hline Total & $62\left(102^{\mathrm{a}}\right)$ \\
\hline $\begin{array}{l}\text { Italic font indicates participation by practitioners in at least some aspect of the study (56/62 studies }= \\
90 \%) . \\
\text { a }>100 \text { as result of rounding individual \% totals. }\end{array}$ \\
\hline
\end{tabular}

Overall, the 62 primary papers identified a total of 96 participant groups. The level of engagement of the participants within the research process was not always possible to ascertain from the papers, and rating participants as being either active or passive within the research process was possible for just 79 participant groups (Table 6). Of these, 57 (72\%) were rated as being actively involved in the research process, for example, by contributing to defining the research area or undertaking the research.

\section{Source of funding}

Twenty-seven papers (44\%) identified that the study had been funded, although five of these did not give the source. Only one study explicitly stated that no funding was involved but it is recognised that some studies may not have actually identified the funding source, especially where internal funding was involved. Of the 22 that did, 15 different sources were identified, suggesting that there is a wide range of funders who support AR. Most (12 studies) were funded through the Workforce Development Confederation (4), the Department of Health (2), Kings Fund (2), a local NHS Primary Care Trust (2) and RSAS Age Care (2). 
Table 6 Level of inclusion of participants in the research process

\begin{tabular}{|c|c|c|}
\hline Group & No. of active participants & No. of passive participants \\
\hline Practitioners $(n=44)$ & 40 & 4 \\
\hline Service users $(n=17)$ & 4 & 13 \\
\hline Carers $(n=5)$ & 4 & 1 \\
\hline Academics $(n=6)$ & 5 & 1 \\
\hline Students $(n=7)$ & 4 & 3 \\
\hline Total $(n=79)$ & $57(72 \%)$ & $22(28 \%)$ \\
\hline
\end{tabular}

\section{Discussion}

Bibliometric analysis presents a number of challenges, including the comprehensivity of the database that is constructed and the validity of making assumptions on the interpretation of material presented within the publications. As noted earlier, the authors make no claims of absolute comprehensivity, although the electronic databases that were searched are predominant in the field. The absence of the two leading UK AR specialist journals from those databases was surprising in view of the relatively high number of papers pertinent to this review that were found within them, and suggests that there may be other publications that did not appear in the search. Nevertheless, the prominence of the databases and journals that were searched leads us to be confident that this review captured sufficient papers to provide a reasonable picture of the uptake of AR within nursing. Assumptions concerning the analysis of material within the papers are identified at points in the previous sections. However, one aim of the study was to gain insight into how AR has been applied, and to identify characteristics of authorship of AR publications. In so doing, it has to be acknowledged that there are a number of potential limitations to the data interpretation. Thus, academic researchers and practitioners may have different agendas, with academics perhaps being under more pressure to publish. Furthermore, the study database possibly included publications of 'one-off' local projects for employers (which may be reflected in any analysis of repeat authorship), and of student research (which may bias authorship towards academic supervisors). Also, service users may publish the study findings in 'grey' literature sources, and practitioners may be more prominent as authors of conference papers. While acknowledging these potential limitations, in terms of changing practice it is also the case that ownership of published research is normally linked to publication within peer-reviewed journals (all the sources in this review came under that category), rather than 'grey' literature and conference papers, whereas ownership of the research and its contribution to knowledge is accredited to the authorship of those papers, particularly the 'lead' authorship. Accordingly, this review has provided an overview of participatory AR in nursing research and of leadership in publishing the research as evidenced by authorship.

On the contrary to the appearance of AR in approximately just $5 \%$ of doctoral study designs (McVicar and Caan, 2005; Hillier, et al., 2006), and in educational research designs published in Nurse Education Today, a leading journal for innovations in nurse education (Long and Johnson, 2005), this review has identified a significant uptake of AR when compared with other methodological approaches that have been dominant in nursing research designs, in particular phenomenology and ethnography. This could indicate a groundswell of research development promoting AR within practice areas; in this review $78 \%$ of the studies had taken place within a health care setting and just $22 \%$ in university settings. Interestingly, a wide range of funders of research was identified as supporting AR. External funding generally is poor within nursing research (Traynor, et al., 2001) and the relatively high identification of funders for the studies in this review is encouraging.

To advocates of AR its greatest appeal is probably its focus on change, a feature that is pivotal in bridging the theory/practice gap (Meyer, 1993; Waterman, et al., 1995). The distinctions between organisational change/practice development and patient care/practitioner development are not always clear, but our assessment indicates that the focus of change in 
the reviewed papers primarily was organisational/practice development. Only $13 \%$ could be defined as having as their focus a direct impact on patient care, and none were focused on policy/funding issues. The emphasis of nursing research on non-clinical research has been emphasised elsewhere (Traynor, et al., 2001; McVicar and Caan, 2005), and AR studies' therefore, appear to be following a similar trend. There is increasing demand for more clinically-focused research, and so the interventional/change aspect of AR would seem to make it an ideal alternative to experimental research designs because it adopts an inclusive stance, encouraging practitioner and service user/carer involvement within the research process itself. This review has identified that more 'traditional' research tools were used by researchers but there also was some evidence of increasing diversity, and the absence of any alignment of any particular method within AR may bode well for the application of innovative research designs in the future.

The review evidenced a high level of collaboration between academics and practitioners, which could mean that any theory/practice gap in the application of AR design for practice development is being addressed by Higher Education institutions. Conversely, it could also mean that academics (albeit professionally-qualified) are still leading the nursing research agenda. Thus, although practitioners may be actively involved in generating knowledge about their practice, the 'lead' authors predominantly came from academic institutions. Furthermore, a relatively high number of papers had sole-authorship, again predominantly academics. Academic personnel, of course, have publication of research within their employment remit and so their agenda may be different to that of other collaborators, but the situation is disappointing from the point of view of promoting collaborative approaches to the research: $90 \%$ of studies involved practitioners as participants, mainly in an 'active' role, and so a greater 'lead' by practitioners might have been anticipated. On a more positive note, authorship of the papers in this review was not dominated by those few academics already recognised as significant leaders of AR in nursing, but largely involved authors (academic or practitioners) who collectively had each collaborated on just one AR project, suggesting that there is a breadth of experience of AR that might, potentially, contribute to future development of nursing education and practice.

However, the real concern has to be the absence of service user/carer involvement in the authorship. Possibly the data reflect the low appearance of the clinical setting for the research, or perhaps the individual's agenda in relation to appearing in a publication may have had an influence, but the small number of service users or carers who were participants in the studies evidences a lack of engagement of researchers with these important groups, despite recommendations to the contrary (Meyer and Sturdy, 2004; Waterman, et al., 2001; Winter and Munn-Giddings, 2001). AR may readily be designed to involve patients/carers even when the focus of the research is not directly clinical, including organisational and professional development-centred study.

\section{Conclusions}

In conclusion, research development within nursing has adopted AR much more strongly than education-based studies imply. As with trends in nursing research generally, most studies related to organisational or professional/educational settings, and relatively few studies could be considered as 'clinical' research. Collaboration in the studies between academics and other groups, notably practitioners, is strong but could be acknowledged more overtly in the authorship of publications - participation should be seen to involve co-ownership, whereas co-authorship and 'lead' authorship are important identifiers of a maturing research culture in health care organisations. A paucity of active involvement of service users in the studies, and as authors, needs to be addressed, particularly if clinical applications of AR designs become more prominent. 


\section{Key Points}

- Action research has a strong presence within nursing research, but mainly focused on organisational/professional development/education settings.

- A diverse range of methods are used evidencing development of a breadth of research skills among practitioners, although what might be considered conventional tools, for example, questionnaire survey and interview, predominate.

- Participation of practitioners within the research process is very strong, but the level of authorship of papers tends to be dominated by academics even to the extent at times of sole authorship. The sources of publication on the whole are also most likely to be read by academics, and presumably recommended to students, who may view this as 'the' knowledge base.

- External funding was evident in a relatively large proportion of the studies reviewed, suggesting an attractiveness of action research to funders.

- Few studies involved service users and/or carers in the research, and virtually none of the authors came from these groups.

\section{References}

Bellman, L (2001) Courage, faith and chocolate cake: requisites for exploring professionalism in action. Educ Action Res 9: 225-242.

Beresford, P (2003) It's Our Lives: A Short Theory of Knowledge, Distance and Experience. London: Citizen's Press in association with Shaping Our Lives.

Beresford, P (2006) Making the connections with direct experience: from the Western Front to user controlled research. Educ Action Res 14: 161-169.

Department of Health (2000) The NHS Plan. A Plan for Investment, a Plan for Reform. London: Department of Health.

Department of Health (2005) Research Governance Framework for Health and Social Care, second ed. London: Department of Health.

Department of Health (2006a) Towards a Strategy for nursing research and development: Proposals for action (August 2000). Nursing and Research and Development Directorates, Department of Health. London: HMSO.

Department of Health (2006b) Best Research for Best Health: A new national health research strategy. London: Department of Health.

Department of Health/Higher Education Funding Council for England (2001) Research in nursing and allied health professions report of Task Group 3 to HEFCE and the Department of Health. London: HMSO.

Hart, E, Bond, M (1995) Action Research for Health and Social Care. A Guide to Practice. Buckingham: Open University.

Hillier, D, Caan, W, McVicar, A (2006) Research training and leadership for midwives and health visitors. Community Pract 80: 28-33.

Holter, IM, Schwartz-Barcott, D (1993) Action research: what is it? How can it be used in nursing. J Adv Nurs 23: 423-425.

Hope, KW, Waterman, $\mathrm{H}$ (2003) Praiseworthy pragmatism? Validity and action research. $J$ Adv Nurs 44: 120-127.

Long, T, Johnson, M (2005) Research in Nurse Education Today: do we meet our aims and scope? Nurse Educ Today 25: 601-608.

McVicar, A, Caan, W (2005) Research capability in doctoral training. Evidence for increased diversity of skills in nursing research. J Res Nurs 10: 627-646.

Meyer, J (1993) New paradigm research in practice: the trials and tribulations of action research. J Adv Nurs 18: 1066-1072.

Meyer, J, Sturdy, D (2004) Exploring the future of gerontological outcomes. J Clin Nurs 13: 128-134. 
National Co-Ordinating Centre for NHS Service Delivery and Organisation Research and Development (2001) Managing Change in the NHS: Organisational change - a Review of Health Care Managers, Professionals and Researchers. London: NCCSDO.

Normand, C, Meyer, J, Bentley, J (2003) Research ethics and complex studies. Nurs Times Res 8: 17-26.

Rolfe, G (1996) Going to extremes: action research, grounded practice and the theorypractice gap in nursing. J Adv Nurs 24: 1315-1320.

Scott, E, McMahon, A, Kitson, A, Rafferty, AM (1999) A national initiative to set priorities for R\&D in nursing, midwifery and health visiting - investigating the method. Nurs Times Res 4: 283-290.

Somekh, B, Burman, E, Delamont, S, Meyer, J, Payne, M, Thorpe, R (2005) Research communities in the social sciences. In: Somekh, B, Lewin, C (eds), Research Methods in the Social Services, Part 1, London: Sage Publications, pp. 1-14.

Taylor, R, Thornicroft, G (1996) Uses and limits of randomised controlled trials in mental health service research. In: Thornicroft, G, Tansella, M (eds), Mental Health Outcomes Measures. Berlin: Springer-Verlag.

Traynor, M, Rafferty, AM, Lewison, G (2001) Endogenous and exogenous research? Findings from a bibliometric study of UK nursing research. J Adv Nurs 34: 212-222.

Walters, S, East, L (2001) The cycle of homelessness in the lives of young mothers: the diagnostic phase of an action research project. J Clin Nurs 10: 171-179.

Waterman, H, Tillen, D, Dickson, R, de Koning, K (2001) Action research: a systematic review and guidance for assessment. Health Technol Assess 5 (On-line). Available at http://www.hta.nhsweb.nhs.uk/fullmono/mon523. pdf (accessed 11.01.08).

Waterman, H, Webb, C, Williamson, A (1995) Parallels and contradictions in the theory and practice of action research and nursing. J Adv Nurs 22: 779-784.

Winter, R, Munn-Giddings, C (eds) (2001) A Handbook for Action Research in Health and Social Care. London: Routledge.

Before joining the University Carol Munn-Giddings (BA, MA, PhD, FHEA; Reader, Faculty of Health and Social Care) worked for many years as a social researcher in various health and social services settings, including the voluntary sector. In these roles she undertook, facilitated and managed projects related to service users' perspectives. She joined Anglia Ruskin University in 1995. Her doctoral research explored the relationship of self-help/mutual aid groups to social policy in the UK. One of her specialist areas is supporting practitioners and service users in undertaking action research and in this capacity she published with Routledge 'A Handbook of Action Research in Health and Social Care' which she co-authored with Professor Richard Winter. Carol is also one of the editorial team of the International Journal Educational Action Research and recently she co-edited a Special Issue on Health and Social Care. She also worked for several years in social and educational development projects in Ukraine.

Andrew McVicar (BSC, PhD, FHEA) has published extensively on issues for nurses and is a member of the Editorial Board of the British Journal of Nursing. He is committed to promoting growth in research capacity and capability of academics and practitioners in health care, and has spent several years in roles related to research development in health and social care within Anglia Ruskin University. He is Director of Research Degree Students within the University's Faculty of Health and Social Care.

Lesley Smith (BSc, MSc, CertEd) is an independent researcher and former Senior Lecturer at Anglia Ruskin University. Over a period of 35 years, Lesley has undertaken many research projects in the fields of health, social care, crime and education and is committed to applied research using participatory methods. She has a wide range of associated publications. 